\title{
Indicadores da NBC T 15: uma análise da adesão no balanço social da EPAMIG
}

A preocupação da população com os aspectos sociais e ambientais nos últimos anos faz com que as empresas se adequem a apresentar informações contábei exigidas pela legislação, além de demonstrarem informações sobre ações sociais e ambientais. Este estudo tem como objetivo principal analisar o nível de adesão dos indicadores da Norma Brasileira de Contabilidade NBC T 15 - Informações de Natureza Social e Ambiental, no balanço social da Empresa de Pesquisa Agropecuária de Minas Gerais (EPAMIG). Para atingir o objetivo foram analisados os balanços sociais da EPAMIG dos anos 2016 e 2017 . Os demonstrativos foram extraídos do site da empresa, e solicitados via Lei de Acesso à Informação, sendo comparados com os indicadores da NBC T 15. O estudo se justifica pela importância da responsabilidade social e ambiental e da contabilidade como ferramenta na apresentação das informações aos interessados. Trata-se de uma pesquisa de caráter descritiva com abordagem qualitativa, com dados obtidos a partir de análise bibliográfica e documental. Constatou-se que a EPAMIG apresenta informações acerca dos recursos humanos, sendo a maior adesão aos indicadores. Por sua vez, as informações sobre a interação com o ambiente externo e com o meio ambiente não apresentaram nenhum indicador proposto na norma.

Palavras-chave: Balanço Social; Responsabilidade Social; Contabilidade; EPAMIG.

\section{NBC T 15 indicators: an analysis of membership in EPAMIG's social balance sheet}

The population's concern with social and environmental aspects in recent years has made companies adequate to present accounting information required by law, in addition to demonstrating information on social and environmental actions. This study has as main objective to analyze the level of adherence of the indicators of the Brazilian Accounting Standard NBC T 15 - Information of Social and Environmental Nature, in the social balance of the Agricultural Research Corporation of Minas Gerais (EPAMIG). To achieve the objective, the social balance sheets of EPAMIG for the years 2016 and 2017 were analyzed. The statements were extracted from the company's website, and were requested via the Access to Information Law, being compared with the NBC T 15 indicators. importance of social and environmental responsibility and accounting as a tool in presenting information to stakeholders. It is a descriptive research with a qualitative approach, with data obtained from bibliographical and documentary analysis. It was found that EPAMIG presents information about human resources, with the highest adherence to the indicators. In turn, the information on the interaction with the external environment and the environment did not present any indicator proposed in the standard.

Keywords: Social Balance; Social Responsibility; Accounting; EPAMIG.

Topic: Demonstrações Contábeis

Reviewed anonymously in the process of blind peer.
Received: 07/01/2021

Approved: 23/03/2021
Tiago de Moura (iD)

Universidade Tecnológica Federal do Paraná, Brasil http://lattes.cnpq.br/2492788495391636

http://orcid.org/0000-0001-5233-4086

tiagomourabh@gmail.com

Amanda David Mamedes (iD)

Universidade Tecnológica Federal do Paraná, Brasil

http://lattes.cnpq.br/6327816770041947

http://orcid.org/0000-0002-0500-4145

amanda.ddm@gmail.com

Sergio Adelar Brun (D)

Universidade Tecnológica Federal do Paraná, Brasil

http://lattes.cnpq.br/8074140112961583

http://orcid.org/0000-0002-8674-331X

sergiobrun@utfpr.edu.br
Referencing this:

MOURA, T.; MAMEDES, A. D.; BRUN, S. A.. Indicadores da NBC T 15: uma análise da adesão no balanço social da EPAMIG. Revista Brasileira de Administração Científica, v.12, n.1, p.291-302, 2021. DOI: http://doi.org/10.6008/CBPC2179-684X.2021.001.0024 


\section{INTRODUÇÃO}

Nos últimos anos está evidente a preocupação da população com os aspectos sociais e ambientais. Neste contexto, as empresas precisam se adequar e não apresentar apenas as demonstrações contábeis exigidas na legislação, mas também apresentar as ações de responsabilidade social e ambiental. As entidades vêm buscando maior compromisso no relacionamento com a sociedade, em relação aos aspectos sociais, com o objetivo de maior legitimidade organizacional, fato que evidencia a forma e conteúdo da evidenciação (BANDEIRA et al., 2019). Conforme Beuren et al. (2010) as empresas precisam evidenciar as ações no campo social, além da situação econômico-financeira, e assim tornar público o comportamento empresarial consciente e responsável.

Silva et al. (2016) afirmam que por conta da globalização, as empresas públicas e privadas tendem a divulgar com maior transparência para seus stakeholders suas demonstrações contábeis. Assim para evidenciar tais ações surge como ferramenta o balanço social. Para Colares et al. (2012) este relatório de informações sociais e ambientais, ainda que seja de divulgação voluntária, vem sendo divulgado com maior frequência entre as empresas e solicitado entre os interessados. Assim surge a pergunta: Qual o nível de adesão dos indicadores da NBC T 15 no balanço social da EPAMIG?

Este estudo tem como objetivo principal analisar o nível de adesão dos indicadores da Norma Brasileira de Contabilidade NBC T 15 - Informações de Natureza Social e Ambiental, no balanço social da Empresa de Pesquisa Agropecuária de Minas Gerais (EPAMIG). Para atingir o objetivo foram analisados os balanços sociais da EPAMIG dos anos 2016 e 2017, os demonstrativos foram extraídos do site da empresa, e também solicitados via Lei de Acesso à Informação e os dados presentes nestes foram comparados com os indicadores presentes na NBC T 15.

Este artigo possui relevância ao tratar de responsabilidade social e ambiental, qualidade na divulgação das informações sociais e ambientais, e a importância da EPAMIG para os agricultores e população em geral ao propor inovações e soluções tecnológicas para melhorar a qualidade de vida destes. A pesquisa é de caráter descritivo com abordagem qualitativa, com dados obtidos com análise bibliográfica de artigos e livros e documental a partir de documentos institucionais da empresa e legislações aplicáveis.

\section{REVISÃO TEÓRICA}

\section{Contabilidade Social e Ambiental}

Eugénio (2010) dispõe que desde meados do século XX é estudada e desenvolvida a implementação de uma Contabilidade Social e Ambiental como complemento da Contabilidade Financeira. Conforme Costa et al. (2020), ao longo dos anos a ciência contábil passou por evolução, acompanhando as mudanças ocorridas na sociedade. Fusco et al. (2019) asseveram que a pesquisa sobre relatórios sociais e ambientais (também denominado Balanço Social) para o setor público ainda está na fase inicial, embora haja crescimento lento, são poucas e localizadas as pesquisas. Deegan (2017) traz um estudo sobre 25 anos de pesquisa na contabilidade social e ambiental, e afirma que houve um aumento na quantidade de entidades 
que prestam contas sociais e ambientais, e há uma crescente literatura tentando de alguma forma explicar quais os motivos que impulsionam este comportamento, muitas vezes voluntário.

Beuren et al. (2011) trazem em seu trabalho que as entidades são pressionadas pela sociedade para que demonstrem a preocupação com o meio ambiente e com as questões sociais, e o mesmo tempo buscam a geração de riqueza. Assim, as entidades precisam demonstrar sua participação na preservação do meio ambiente e na valorização da sociedade em geral.

A contabilidade voltada para o meio ambiente não é uma técnica nova, mas sim apenas uma tendência da contabilidade tradicional (GOMES et al., 2020). Pelo lado social, Ramos et al. (2020) trazem em seu estudo que o sistema de informação contábil, que é originário do desenvolvimento humano, precisou estender seu olhar além do enfoque financeiro e econômico, visto que enfoque social começou a ser exigido devido a reporte de informações à vários stakeholders.

\section{Norma brasileira de contabilidade NBC T 15}

O Conselho Federal de Contabilidade (CFC) aprovou a Norma Brasileira de Contabilidade NBC T 15 Informações de Natureza Social e Ambiental, no dia 19 de agosto de 2004, por meio da Resolução CFC no 1003/2004. O início da vigência seria em 1 de janeiro de 2006, mas o CFC recomendou a sua adoção antecipada. A norma estabelece os procedimentos para que as informações sociais e ambientais sejam demonstradas e tem como objetivo "demonstrar à sociedade a participação e a responsabilidade social da entidade" (BRASIL, 2004).

Conforme Silva (2015) a NBC T 15 está no "campo das conquistas em prol da transparência das informações de caráter social sobre empresas no Brasil", os autores ainda destacam o nível de transparência da norma, indo ao encontro da responsabilidade social. Esta norma traz uma forma para que as empresas apresentem informações referentes a questões ambientais e sociais, deixando de atender apenas para atender as exigências e objetivos de caráter financeiro dos acionistas, como era no passado, conforme afirmam Ramos et al. (2020).

De acordo com CFC (BRASIL, 2004), entende-se como informação de natureza social e ambiental: a) a geração e a distribuição de riqueza; b) os recursos humanos; c) a interação da entidade com o ambiente externo; d) a interação com o meio ambiente.

Essas quatro dimensões podem ser divulgadas de acordo com os procedimentos determinados pela NBC T 15. A primeira dimensão refere-se à riqueza gerada e distribuída pela empresa e pode ser apresentado conforme a Demonstração do Valor Adicionado. De acordo com Azevedo et al. (2020), o valor adicionado representa uma forte contribuição para o produto interno da nação, sendo medido pela extensão do valor do produto quando é adquirido pela empresa e o ponto em que é vendido ou disponibilizado.

No âmbito das informações sobre os recursos humanos devem constar dados referentes à remuneração, benefícios concedidos, composição do corpo funcional e as contingências e os passivos trabalhistas da entidade e outras informações como remuneração e benefícios concedidos aos empregados, administradores, terceirizados e autônomos. A interação da entidade com o ambiente externo está ligada ao 
relacionamento com a comunidade, com os clientes e fornecedores. A interação da com o meio ambiente refere-se a investimentos e gastos com manutenção nos processos operacionais para a sua melhoria e preservação (BRASIL, 2004).

\section{Responsabilidade social corporativa}

Beuren et al. (2011) afirmam que a questão da responsabilidade socioambiental por parte da sociedade teve surgimento quando está sociedade se deu conta da primazia dos direitos humanos e da finitude dos recursos ambientais. Conforme Ghobadian et al. (2015) o conceito de responsabilidade corporativa $(\mathrm{RC})$ percorreu um longo caminho nas últimas seis décadas.

A demanda por divulgação social e ambiental corporativa por parte de entidades públicas aumentou nas últimas duas décadas (GIACOMINI et al., 2020). Uma das ferramentas para esta divulgação é o balanço social, também denominado de relatório de informações sociais e ambientais que será apresentado no tópico seguinte.

\section{Balanço social}

Sobre as demonstrações contábeis, Glaserová (2013) afirma que estas representam o produto final da contabilidade, na forma de um complexo estruturado com as informações necessárias para todos os usuários, sejam internos ou externos. Estas são a base para tomada de decisões por parte dos usuários. Beuren et al. (2011) dispõe que a contabilidade faz uso de um conjunto de demonstrações contábeis e relatórios complementares que divulgam informações relacionadas às atividades de uma empresa e apresentam informações qualitativas e quantitativas sobre a situação econômico-financeira e patrimonial de uma empresa. Assim tais relatório podem revelar, de forma voluntária, assuntos que interessam a um grande número usuários da contabilidade, incluindo informações sobre questões sociais e ambientais.

Assim temos o balanço social (também denominado relatório social ou relatório de informações sociais e ambientais) que segundo Silva et al. (2015) pode auxiliar as empresas a prestar contas dos projetos, benefícios e ações sociais desenvolvidos pelas organizações. Cardillo et al. (2020) afirmam que esta demonstração, como parte dos sistemas contábeis tradicionais, é essencial para o apoio às decisões de formuladores de políticas na promoção da sustentabilidade social e avaliação de efeitos das escolhas destas internamente e externamente em relação aos stakeholders.

Mesmo não sendo obrigado pela legislação, o balanço social é uma demonstração importante para prestação de contas das entidades para a população e sociedade em geral, assim Slomski (2009), expõe que "na administração pública é, certamente, onde mais deve estar presente a filosofia da accountability" a razão para esta afirmação se deve pois quando a sociedade elege seus representantes, espera que estes ajam em seu nome de forma correta e que prestem contas de seus atos.

Conforme exposto no Quadro 1, a estrutura proposta pelo Conselho Federal de Contabilidade apresenta uma diversidade informações que podem atender a diversos usuários das demonstrações contábeis. Também é evidente que a norma não limita apresentação de informações contábeis apenas, mas 
também apresenta informações de cunho social e ambiental.

Quadro 1: Estrutura do Balanço Social conforme NBC T 15.

\begin{tabular}{|l|l|}
\hline Tipo da Informação & Descrição \\
\hline $\begin{array}{l}\text { Deração e } \\
\text { Riqueza }\end{array}$ & $\begin{array}{l}\text { A riqueza gerada e distribuída pela entidade deve ser apresentada conforme a Demonstração do Valor } \\
\text { Adicionado, definida na NBC TG 09 - Demonstração do Valor Adicionado (riqueza criada pela empresa, de } \\
\text { forma geral medida pela diferença entre o valor das vendas e os insumos adquiridos de terceiros. Inclui } \\
\text { também o valor adicionado recebido em transferência, ou seja, produzido por terceiros e transferido à } \\
\text { entidade). }\end{array}$ \\
\hline Recursos Humanos & $\begin{array}{l}\text { Devem constar dados referentes à remuneração, benefícios concedidos, composição do corpo funcional e } \\
\text { as contingências e os passivos trabalhistas da entidade. Quanto à remuneração e benefícios concedidos } \\
\text { aos empregados, administradores, terceirizados e autônomo. As informações devem ser expressas } \\
\text { monetariamente pelo valor total do gasto com cada item e a quantidade de empregados, autônomos, } \\
\text { terceirizados e administradores beneficiados. }\end{array}$ \\
\hline $\begin{array}{l}\text { Interação da } \\
\text { Entidade com o }\end{array}$ & $\begin{array}{l}\text { Devem constar dados sobre o relacionamento com a comunidade na qual a entidade está inserida, com } \\
\text { os clientes e com os fornecedores, inclusive incentivos decorrentes dessa interação. }\end{array}$ \\
\hline $\begin{array}{l}\text { Interação com o } \\
\text { Meio Ambiente }\end{array}$ & $\begin{array}{l}\text { São evidenciados investimentos e gastos com manutenção nos processos operacionais para a melhoria do } \\
\text { meio ambiente; com a preservação e/ou recuperação de ambientes degradados; com a educação } \\
\text { ambiental para empregados, terceirizados, autônomos e administradores da entidade; com educação } \\
\text { ambiental para a comunidade; com outros projetos ambientais; quantidade de processos ambientais, } \\
\text { administrativos e judiciais movidos contra a entidade; valor das multas e das indenizaçães relativas à } \\
\text { matéria ambiental, determinadas administrativa e/ou judicialmente; passivos e contingências ambientais }\end{array}$ \\
\hline
\end{tabular}

Fonte: BRASIL (2004).

\section{METODOLOGIA}

Neste tópico será apresentada a metodologia utilizada para atingir os objetivos da pesquisa. Por apresentar a descrição das características de um fenômeno, esta pesquisa quanto a seus propósitos pode ser definida como descritiva (GIL, 2018). É qualitativa por buscar compreender um fenômeno em seu ambiente natural (KRIPKA et al., 2016). A forma de coleta dos dados é classificada como uma pesquisa bibliográfica e documental. Bibliográfica por ser elaborada com base em material já publicado (GIL, 2018), neste caso ocorreu a pesquisa em artigos e livros. Pesquisa documental, pois houve análise de documentos institucionais da EPAMIG e legislações aplicáveis ao relatório de informações sociais e ambientais e legislações do estado de Minas Gerais.

Os balanços sociais foram obtidos por meio do sítio eletrônico da EPAMIG, mas também foram solicitados por meio de um pedido elaborado com base na Lei de Acesso à Informação, protocolo no 03050000005202097, cuja resposta foi a informação de onde encontrar os balanços no site. Portanto a resposta foi de acordo com os documentos dispostos no site. A seguir um trecho da resposta ao pedido de acesso à informação:

Diante do pedido realizado, temos a informar que:

1- $O$ documento balanço Social foi publicado em 2 edições apenas. Esse documento não foi elaborado em atendimento a normativo interno ou legislação especifica, no entanto atende em parte as colocações da Lei Federal no 13.303 em seu artigo 8.

$[\ldots]$

Os balanços sociais da EPAMIG são publicados no site da empresa www.epamig.br, com destaque em homepage no ano de sua publicação e até que seja publicada nova edição. Após este prazo eles ficam disponíveis no mesmo sítio eletrônico.

Encerrando a apresentação da metodologia utilizada, o estudo parte para a análise dos dados coletados. 


\section{RESULTADOS E DISCUSSÃO}

\section{Análise dos dados}

A Empresa de Pesquisa Agropecuária de Minas Gerais - EPAMIG, empresa pública do estado de Minas Gerais, foi criada pela Lei no 6.310, de 08 de maio de 1974 com a finalidade desenvolver pesquisas e experimentações relacionadas direta e indiretamente, com a agropecuária. A empresa tem referenciais estratégicos que estão descritos na figura 1.

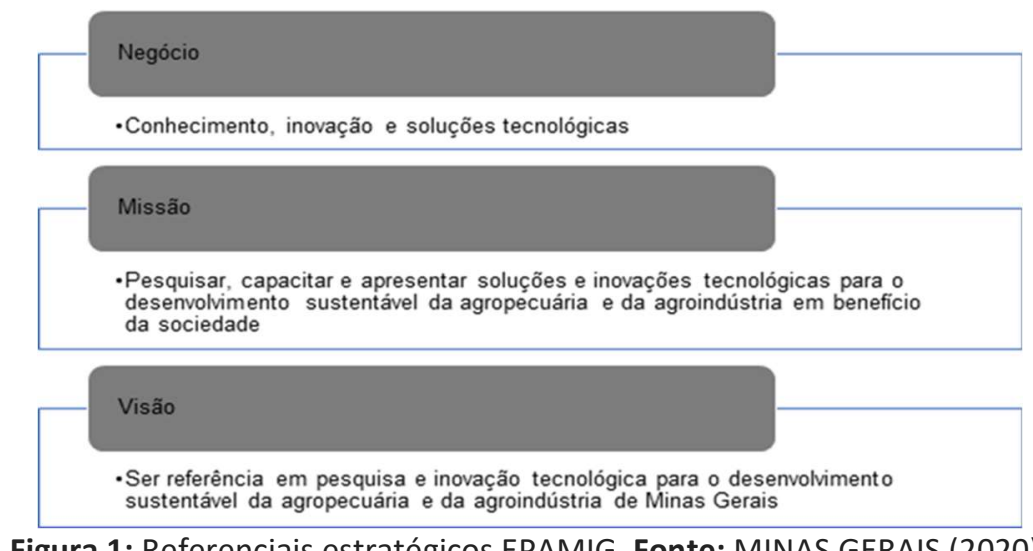

A empresa pública estudada é sediada em Belo Horizonte, Minas Gerais. Em resposta ao questionamento efetuado via Sistema Eletrônico do Serviço de Informação ao Cidadão, protocolo 03050000006202031, foi informado que o quantitativo atualizado de empregados da EPAMIG, em 31/07/2020, é de 591 empregados efetivos, 53 oriundos de recrutamentos amplos e 03 aprendizes pagos na folha, totalizando em 647 empregados públicos pagos com recursos do estado de Minas Gerais e 79 safristas pagos com recurso próprio.

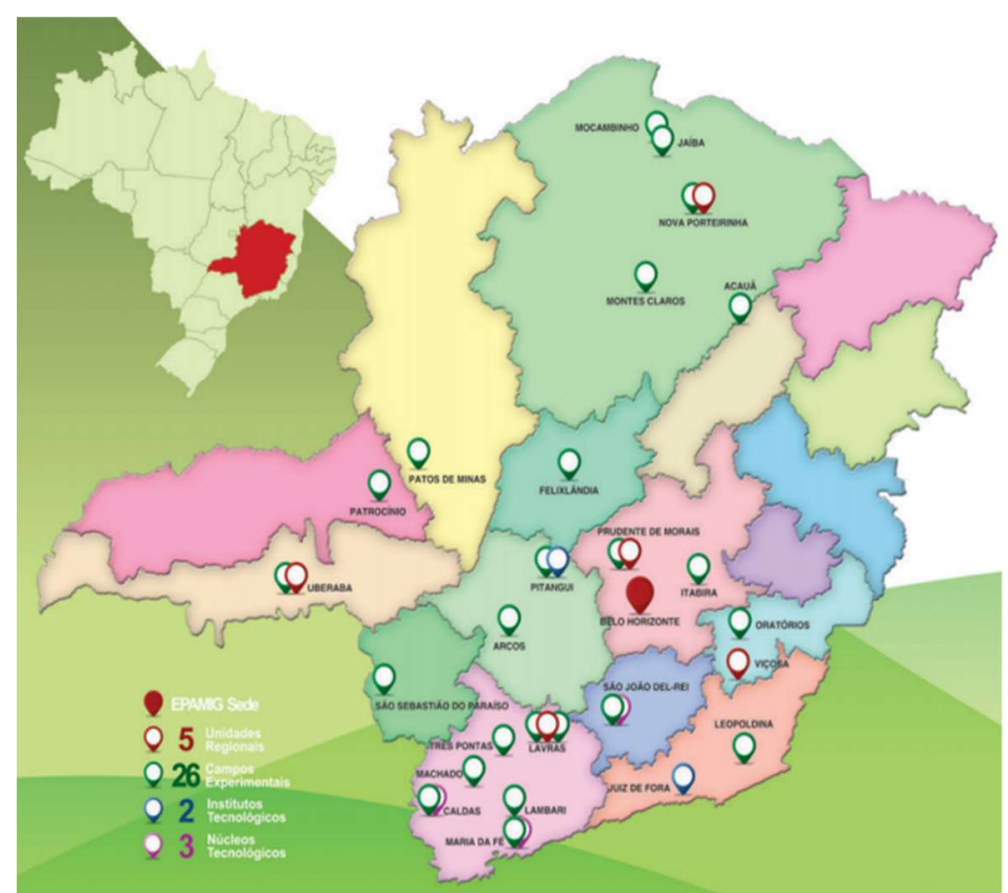

Figura 2: Unidades da EPAMIG. Fonte: MINAS GERAIS (2016). 
A empresa possui uma estrutura descentralizada, para que consiga atender às necessidades dos produtores rurais de diversas regiões de Minas Gerais e do Brasil. Com a Sede Administrativa, em Belo Horizonte, a empresa ainda possui cinco unidades regionais, dois núcleos de ensino, três núcleos tecnológicos e 26 campos experimentais (MINAS GERAIS, 2016).

A figura 2 ilustra a localização das unidades, núcleos de ensino, núcleos tecnológicos e os campos experimentais espalhados pelo território do estado de Minas Gerais.

Em seu sítio eletrônico, no link documentos institucionais são apresentados diversos documentos, dentre eles o Balanço Social de 2016 e outro denominado Balanço Social 2017/2018, mas que ao observar o balanço em si, só possui dados referentes ao ano de 2017. Portanto, serão apresentados os balanços sociais de 2016 e 2017 além de ser efetuada a análise do balanço social da EPAMIG.

Quadro 2: Balanço Social EPAMIG, 2016 e 2017.

\begin{tabular}{|c|c|c|c|c|c|c|}
\hline 1 Base de Cálculo & \multicolumn{3}{|c|}{2017 - Valores em Reais } & \multicolumn{3}{|c|}{2016 - Valores em Reais } \\
\hline $\begin{array}{l}\text { Receita } \\
\text { Operacional } \\
\text { Líquida (ROL)* }\end{array}$ & \multicolumn{3}{|l|}{$8.694 .839,08$} & \multicolumn{3}{|l|}{$7.407 .541,16$} \\
\hline $\begin{array}{l}\text { Receita } \\
\text { Operacional (RO) }\end{array}$ & \multicolumn{3}{|l|}{$-1866.344,14$} & \multicolumn{3}{|l|}{$6.516 .948,72$} \\
\hline $\begin{array}{ll}\text { Folha } & \text { de } \\
\text { Pagamento** } & \end{array}$ & \multicolumn{3}{|l|}{$96.180 .246,50$} & \multicolumn{3}{|l|}{$91.517 .409,59$} \\
\hline $\begin{array}{l}\text { Empresas } \\
\text { Prestadoras de } \\
\text { Serviços }\end{array}$ & \multicolumn{3}{|l|}{$1.887 .974,32$} & \multicolumn{3}{|l|}{1.885 .221 .93} \\
\hline $\begin{array}{ll}2 & \text { Indicadores } \\
\text { Sociais } & \text { Internos }\end{array}$ & Valor & \% sobre FPB & \% sobre ROL & Valor & $\begin{array}{l}\text { \%sobre } \\
\text { FPB }\end{array}$ & \% sobre RL \\
\hline Alimentação & $6.199 .119,46$ & 6,44 & 71,29 & $5.649 .056,21$ & 6,17 & 76,26 \\
\hline $\begin{array}{l}\text { Encargos Sociais } \\
\text { Compulsórios }\end{array}$ & $25.256 .882,47$ & 26,26 & 290,48 & $24.086 .610,44$ & 26,32 & 325,16 \\
\hline $\begin{array}{l}\text { Previdência } \\
\text { Privada }\end{array}$ & $3.377 .116,86$ & 3,51 & 38,84 & $3.121 .923,20$ & 3,41 & 42,15 \\
\hline $\begin{array}{l}\text { Bem-estar, saúde e } \\
\text { segurança no } \\
\text { trabalho }\end{array}$ & $1.873 .738,65$ & 1,94 & 21,55 & $1.816,336,14$ & 1,98 & 24,52 \\
\hline $\begin{array}{l}\text { Educação } \\
\text { formação } \\
\text { profissional }\end{array}$ & $2.521,64$ & 0,00 & 0,02 & $2.240,40$ & 0,00 & 0,03 \\
\hline $\begin{array}{l}\text { Creches ou Auxílio- } \\
\text { creche }\end{array}$ & $98.572,41$ & 0,10 & 1,13 & $102.744,38$ & 0,11 & 1,39 \\
\hline Outros Benefícios & $366.510,10$ & 0,38 & 4,21 & $339.420,69$ & 0,37 & 4,58 \\
\hline $\begin{array}{l}\text { Total - Indicadores } \\
\text { Laborais Internos }\end{array}$ & $37.174,461,59$ & 38,65 & 427,54 & $35.118 .331,46$ & 38,37 & 474,09 \\
\hline $\begin{array}{l}3 \text { Indicadores } \\
\text { Sociais Externos }\end{array}$ & Valor & \% sobre FPB & \% sobre ROL & Valor & $\begin{array}{l}\% \text { sobre } \\
\text { FPB }\end{array}$ & \% sobre RL \\
\hline $\begin{array}{l}\text { Tributos (Excluídos } \\
\text { Encargos Sociais) }\end{array}$ & $754.275,73$ & 0,78 & 8,67 & $487.961,20$ & 0,53 & 6.59 \\
\hline $\begin{array}{l}\text { Total - Indicadores } \\
\text { sociais externos }\end{array}$ & $754.275,73$ & 0,78 & 8,67 & & & \\
\hline \begin{tabular}{ll}
4 & \multicolumn{2}{c}{ Tecnologias } \\
Desenvolvidas & e \\
Transferidas à & à \\
Sociedade (TD) & \\
\end{tabular} & $983.334 .113,44$ & $1.022,39$ & 11309,40 & $608.686 .951,08$ & 665,11 & $8.217,13$ \\
\hline $\begin{array}{l}5 \quad \text { Lucro Social } \\
(2+3+4)\end{array}$ & $1.021 .262 .850,76$ & $1.061,82$ & $11.745,62$ & $644.293 .243,74$ & 704,01 & $8.697,80$ \\
\hline \multicolumn{7}{|c|}{6 Indicadores do Corpo Funcional } \\
\hline $\begin{array}{l}\text { № de Empregados } \\
\text { ao Final do Período }\end{array}$ & \multicolumn{3}{|l|}{876} & \multicolumn{3}{|l|}{889} \\
\hline $\begin{array}{l}\text { № de Admissões } \\
\text { Durante o Período }\end{array}$ & \multicolumn{3}{|l|}{0} & \multicolumn{3}{|l|}{4} \\
\hline
\end{tabular}




\begin{tabular}{|c|c|c|}
\hline $\begin{array}{l}\text { № de Estagiários e } \\
\text { Menores } \\
\text { Aprendizes }\end{array}$ & 51 & 52 \\
\hline $\begin{array}{l}\text { № de Empregados } \\
\text { Acima de } 45 \text { anos }\end{array}$ & 770 & 694 \\
\hline $\begin{array}{l}\text { № de Mulheres } \\
\text { que Trabalham na } \\
\text { Empresa }\end{array}$ & 273 & 282 \\
\hline $\begin{array}{l}\% \text { de Cargos de } \\
\text { Chefia Ocupados } \\
\text { por Mulheres }\end{array}$ & 20 & 20 \\
\hline $\begin{array}{l}\text { \% de Cargos de } \\
\text { Chefia Ocupados } \\
\text { por Negros }\end{array}$ & 4 & 4 \\
\hline $\begin{array}{l}\text { № de Pessoas com } \\
\text { Necessidades } \\
\text { Especiais }\end{array}$ & 5 & 5 \\
\hline \multicolumn{3}{|c|}{7 Informações Relevantes Quanto ao Exercício da Cidadania Empresarial } \\
\hline $\begin{array}{l}\text { Relação entre a } \\
\text { maior e a menor } \\
\text { remuneração na } \\
\text { empresa }\end{array}$ & 22,91 & 23,81 \\
\hline $\begin{array}{ll}\text { Número total de } \\
\text { acidentes } & \text { de } \\
\text { trabalho } & \\
\end{array}$ & 10 & 10 \\
\hline $\begin{array}{l}\text { Projetos Sociais e } \\
\text { Ambientais são } \\
\text { definidos por }\end{array}$ & $\begin{array}{l}\text { ( ) Direção } \\
\text { (X) Direção e Gerência } \\
\text { ( ) Direção Empregados e Beneficiários }\end{array}$ & $\begin{array}{l}\text { ( ) Direção } \\
\text { (X) Direção e Gerência } \\
\text { ( ) Direção Empregados e Beneficiários }\end{array}$ \\
\hline $\begin{array}{lr}\text { Padrões } & \text { de } \\
\text { segurança } & \text { e } \\
\text { salubridade } & \text { no } \\
\text { ambiente } & \text { de } \\
\text { trabalho } & \text { são } \\
\text { definidos por } & \end{array}$ & $\begin{array}{l}\text { ( ) Direção } \\
\text { (X) Direção e Gerência } \\
\text { ( ) Empregados e CIPA }\end{array}$ & $\begin{array}{l}\text { ( ) Direção } \\
\text { (X) Direção e Gerência } \\
\text { ( ) Empregados e CIPA }\end{array}$ \\
\hline $\begin{array}{l}\text { A previdência } \\
\text { privada contempla }\end{array}$ & $\begin{array}{l}\text { ( ) Direção } \\
\text { ( ) Direção e Gerência } \\
\text { (X) Todos (as) os (as) empregados (as) }\end{array}$ & $\begin{array}{l}\text { ( ) Direção } \\
\text { ( ) Direção e Gerência } \\
\text { (X) Todos (as) os (as) empregados (as) }\end{array}$ \\
\hline 8 Notas & $\begin{array}{l}\text { * A Receita Operacional Líquida (RL) corresponde às } \\
\text { receitas com vendas de produtos e serviços, deduzidos } \\
\text { os descontos incondicionais, as devoluções e os } \\
\text { impostos } \\
\text { ** O orçamento do Estado de Minas Gerais, aprovado } \\
\text { pela Lei no } 22.476 \text { de } 29 / 12 / 16 \text { prevê o repasse de } \\
\text { recursos do Tesouro Estadual para as despesas com } \\
\text { remuneração de pessoal ativo e encargos sociais da } \\
\text { EPAMIG }\end{array}$ & $\begin{array}{l}\text { * A Receita Operacional Líquida (RL) corresponde } \\
\text { às receitas com vendas de produtos e serviços, } \\
\text { deduzidos os descontos incondicionais, as } \\
\text { devoluções e os impostos } \\
\text { ** O orçamento do Estado de Minas Gerais, } \\
\text { aprovado pela Lei no } 21.736 \text { de } 04 / 08 / 15 \text { prevê o } \\
\text { repasse de recursos do Tesouro Estadual para as } \\
\text { despesas com remuneração de pessoal ativo e } \\
\text { encargos sociais da EPAMIG }\end{array}$ \\
\hline
\end{tabular}

Fonte: Adaptado de MINAS GERAIS (2017; 2018).

Com relação ao primeiro indicador da NBC T 15, que trata da geração e distribuição da riqueza, houve apresentação parcial no Balanço Social da EPAMIG. Embora não tenha sido apresentado no formato da Demonstração do Valor Adicionado que a norma sugere, demonstra importantes informações acerca da riqueza criada e distribuída.

As informações acerca dos recursos humanos foram apresentadas parcialmente. Percebe-se que no Balanço Social os indicadores sociais internos, os indicadores do corpo funcional e informações relevantes quanto ao exercício da cidadania empresarial são apresentados com diversos indicadores.

No que diz respeito à interação da entidade com o ambiente externo e a interação com o meio ambiente não houve nenhuma informação no demonstrativo. O quadro 3 demonstra os itens que tiveram adesão ou não. 
Quadro 3: Nível de adesão por informação.

Itens de informação presentes na NBC T 15.

Adesão no Balanço Social da EPAMIG?

A) Geração e Distribuição de Riqueza

1) Receitas

Vendas de mercadorias, produtos e serviços

Outras receitas

Receitas relativas à construção de ativos próprios

Perda estimada para créditos de liquidação duvidosa - Reversão / (Constituição)

Parcial

Parcial .Não detalhado

Parcial. Não detalhado

2) Insumos Adquiridos de Terceiros (inclui os tributos ISS, ICMS, IPI, PIS e COFINS)

Não

Custos dos produtos, das mercadorias e dos serviços vendidos

Não

Materiais, energia, serviços de terceiros e outros

Perda / Recuperação de valores ativos

Outras

3) Valor Adicionado Bruto (1-2)

4) Depreciação/Amortização/Exaustão

5) Valor Adicionado Líquido (3-4)

6)Valor Adicionado Recebido em Transferência

Resultado de equivalência patrimonial

Receitas financeiras

direitos de franquia)

7) Valor Adicionado Total a Distribuir (6+7)

8) Distribuição do Valor Adicionado (0 total do item 8 deve ser igual o total do item 7

Pessoal

Remuneração Direta

Benefícios

FGTS

Impostos/Taxas/Contribuições

Remuneração de capitais de terceiros (juros, alugueis)

Remuneração de Capitais Próprios

B-Recursos Humanos

Remuneração Bruta

Não

Não

Não

Não

Não

Não

Não

Não

Não

Não

Relação entre a maior e a menor remuneração da entidade, considerando os servidores e os contratados

Gastos com encargos sociais

Gastos com alimentação

Gastos com transporte

Gastos com previdência privada

Gastos com saúde

Gastos com segurança e medicina do trabalho

Gastos com cultura

Gastos com educação (excluídos os de educação ambiental)

Gastos com capacitação e desenvolvimento profissional

Gastos com creches ou auxílio-creches

Participações nos lucros ou resultados Não

Parcial, conforme itens a seguir.

Sim

Não

Sim

Sim

Sim (mas não detalhado por esfera)

Não

Não

Composição dos Recursos Humanos

Total de empregados no final do exercício

Total de contratados no final do exercício

Total de contratações (admissões)

Total de demissões

Total de estagiários no final do exercício

Total de empregado portadores de necessidades especiais no final do exercício

Total de contratados por gênero

Empregados Menores de 18 anos

Sim (mas não detalhada)

De 18 a 35 anos, de 36 a 60,

Formação escolar

Percentual de ocupantes de cargos de direção e chefia

Homens

Mulheres

Negros

Pessoas com deficiência

Sim

Sim

Sim

Não

Sim

Sim

Sim

Não

Sim

Sim

Sim

Não

\begin{tabular}{l|}
\hline Sim \\
Sim \\
Não \\
Sim \\
Sim \\
Não \\
Sim (junto com estagiários) Considerou- \\
se menores aprendizes. \\
\hline Não (Apenas Acima de 45 anos que \\
informam a quantidade) \\
\hline Não \\
\hline Parcial, conforme a seguir \\
\hline Não \\
Sim \\
\hline Sim \\
\hline Não
\end{tabular}




\begin{tabular}{|c|c|}
\hline Ações trabalhistas movidas pelos servidores e contratados contra a entidade & Não \\
\hline \multicolumn{2}{|l|}{ C - Interação com a Comunidade } \\
\hline Investimentos em educação, exceto a de caráter ambiental & $\begin{array}{l}\text { Não (Apenas apresenta quem define } \\
\text { projetos sociais e ambientais) }\end{array}$ \\
\hline Investimentos em cultura & $\begin{array}{l}\text { Não (Apenas apresenta quem define } \\
\text { projetos sociais e ambientais) }\end{array}$ \\
\hline Investimentos em saúde e saneamento & $\begin{array}{l}\text { Não (Apenas apresenta quem define } \\
\text { projetos sociais e ambientais) }\end{array}$ \\
\hline $\begin{array}{l}\text { Investimento em esporte e lazer, não considerados os patrocínios com finalidade } \\
\text { publicitária }\end{array}$ & $\begin{array}{l}\text { Não (Apenas apresenta quem define } \\
\text { projetos sociais e ambientais) }\end{array}$ \\
\hline Investimento em alimentação & $\begin{array}{l}\text { Não (Apenas apresenta quem define } \\
\text { projetos sociais e ambientais) }\end{array}$ \\
\hline Reclamações recebidas diretamente na entidade & Não \\
\hline Reclamações recebidas por meio dos órgãos de proteção e defesa do consumidor & Não \\
\hline Reclamações recebidas por meio da Justiça & Não \\
\hline Reclamações atendidas em cada instância arrolada & Não \\
\hline $\begin{array}{l}\text { Montante de multas e indenizações a clientes, determinadas por órgãos de proteção } \\
\text { e defesa do consumidor ou pela Justiça }\end{array}$ & Não \\
\hline \multicolumn{2}{|l|}{ D - Interação com o Meio Ambiente } \\
\hline $\begin{array}{l}\text { Investimentos e gastos com manutenção nos processos operacionais para a melhoria } \\
\text { do meio ambiente }\end{array}$ & Não \\
\hline $\begin{array}{l}\text { Investimentos e gastos com a preservação e/ou recuperação de ambientes } \\
\text { degradados }\end{array}$ & Não \\
\hline $\begin{array}{l}\text { Investimentos e gastos com a educação ambiental para servidores, contratados, } \\
\text { terceirizados, autônomos e gestores da entidade }\end{array}$ & Não \\
\hline Investimentos e gastos com educação ambiental para a comunidade & Não \\
\hline $\begin{array}{l}\text { Quantidade de processos ambientais, administrativos e judiciais movidos contra a } \\
\text { entidade }\end{array}$ & Não \\
\hline $\begin{array}{l}\text { Valor das multas e das indenizações relativas à matéria ambiental, determinadas } \\
\text { administrativa e/ou judicialmente }\end{array}$ & Não \\
\hline Passivos e contingências ambientais & Não \\
\hline
\end{tabular}

Fonte: BRASIL (2004) e MINAS GERAIS (2017; 2018).

Conforme o Quadro 3, pode-se constatar que foi parcial a adesão de indicadores presentes na NBC T 15, principalmente aqueles que estão ligados aos recursos humanos. No próximo tópico serão feitas as considerações finais acerca deste estudo.

\section{CONCLUSÕES}

Levando em consideração que o objetivo deste trabalho foi identificar o nível de adesão do balanço social da EPAMIG aos itens propostos pela Norma Brasileira de Contabilidade NBC T 15, pode se constatar que a empresa mineira apresenta parcialmente os indicadores. Quanto à geração de riqueza os indicadores de receita foram incompletos, visto que as receitas não foram detalhadas e também foram deduzidos os tributos, já na NBC T 15 as receitas devem ser detalhadas e sem dedução dos tributos. Ainda sobre a geração de riqueza que chegará ao valor adicionado a distribuir, não houve adesão à mensuração de depreciação, amortização e exaustão, receitas financeiras, aluguéis, provisões para devedores e reversões. Quanto à distribuição da riqueza, a distribuição é possível constatar nos indicadores de tributos, folha de pagamento. Mas, por outro lado não foram aderidos os indicadores sobre pagamentos de aluguéis.

Quanto aos recursos humanos também a adesão foi parcial, porém a informação com o maior nível de indicadores, sendo os indicadores sociais internos, indicadores de corpo funcional e informações relevantes quanto à cidadania empresarial. Este achado é muito importante, visto que a empresa conta com um número significativo de empregados no geral. Desta parte do balanço social, entre os poucos indicadores 
ausentes pôde-se constatar gastos com transporte, gastos com cultura, e participação nos lucros, porém no Balanço Social da EPAMIG há a indicação de 'outros benefícios', então por falta de uma nota explicativa não há como afirmar que estes indicadores estão inclusos nesta seção.

Por fim os indicadores relativos às informações de interação da entidade com o ambiente externo e a interação com o meio ambiente, o demonstrativo não apresentou nenhum indicador conforme aqueles propostos na estrutura da NBC T 15. Portanto constata-se que a empresa por meio de seu balanço social não presta contas de maneira adequada aos usuários externos, visto que não apresentou diversos indicadores, principalmente aqueles relacionados ao meio ambiente e interação com a comunidade.

A pesquisa teve os objetivos alcançados, ao comparando dois balanços sociais publicados pela EPAMIG. Assim espera também contribuir para futuros estudos, onde se sugere a comparação entre empresas públicas do mesmo porte e segmento, também a verificação de adesão de indicadores de outros modelos de relatórios de informação social e ambiental propostos.

\section{REFERÊNCIAS}

AZEVEDO, E. P. R. S.; LIMA, A. C. S.; FREITAS, M. A. L.. Análise da relação entre o produto interno bruto e o valor adicionado dos estados brasileiros no período de 2010 a 2014. Revista de Auditoria, Governança e Contabilidade, v.8, p.95-111, 2020.

BANDEIRA, M. L.; OLIVEIRA, N. L.; NUNES, A.. Disclosure social: uma análise sob a ótica da NBC T 15 em empresas de capital aberto. Revista Negócios em Projeção, v.10, p.14-29, 2019.

BRASIL. Conselho Federal de Contabilidade. Resolução CFC n. 1.003 de 19 de agosto de 2004. Aprova a NBC T 15: Informações de Natureza Social e Ambiental. Brasília: CFC, 2004.

BEUREN, I. M.; BOFF, M. L.; HORN, J. E.; HORN, M. A.. Adequação da evidenciação social das empresas de capital aberto no relatório da administração e notas explicativas às recomendações da NBC T 15. Revista de Contabilidade e Organizações, v.4, n.8, p.47-68, 2010.

BEUREN, I. M. BOFF, M. L.. Predominant strategies of legitimacy in environmental and social disclosures. Management Research, v.9, n.1, p.56-72, 2011. DOI: https://doi-org.ez48.periodicos.capes.gov.br/10.1108/1536541111146641

CARDILLO, E.; LONGO, M. C.. Managerial Reporting Tools for Social Sustainability: Insights from a Local Government Experience. Sustainability, v.12, n.3675, 2020.

COLARES, A. C. V.; BRESSAN, V. G. F.; LAMOUNIER, W. M.; BORGES, D. L.. O balanço social como indicativo socioambiental das empresas do índice de sustentabilidade empresarial da BM\&F BOVESPA. Revista de Contabilidade do Mestrado em Ciências Contábeis da UERJ, v.17, p.83100, 2012.

COSTA, W. P. L. B.; SILVA, A. K. A.; SILVA, J. D.; NASCIMENTO, Í. C. S. N.; FELIX JÚNIOR, L. A.. Convergência internacional e os desafios ao ensino e profissão contábil. Revista Sítio
Novo, Palmas, v.4, n.3, 2020. Dol:

http://dx.doi.org/10.47236/2594-7036.2020.v4.i3.7-17p

DEEGAN, C.. Twenty five years of social and environmental accounting research within Critical Perspectives of Accounting: Hits, misses and ways forward. Critical Perspectives on Accounting, n.4, p.65-87, 2017. DOI: https://doi.org/10.1016/J.CPA.2016.06.005

EUGÉNIO, T.. Avanços na divulgação de informação social e ambiental pelas empresas e a teoria da legitimidade. Revista Universo Contábil, Blumenau, v.6, n.1, p.102-118, 2010. DOI: $\underline{\text { http://dx.doi.org/10.4270/ruc.20106 }}$

FUSCO, F.; RICCI P.. What is the stock of the situation? A bibliometric analysis on social and environmental accounting research in public sector. Int. J. Public. Sect. Manag., v.32, n.1, p.21-41, 2019. DOI: https://doiorg.ez48. periodicos.capes.gov.br/10.1108/IJPSM-05-2017$\underline{0134}$

GHOBADIAN, A.; MONEY, K.; HILLENBRAND, C.. Corporate responsibility research: Past-present-future. Group \& Organization Management, v.40, n.2, p.271-294, 2015. DOI: https://doi.org/10.1177/1059601115590320

GIACOMINI, D.; ZOLA, P.; PAREDI, D.; MAZZOLENI, M.. Environmental disclosure and stakeholder engagement via social media: State of the art and potential in public utilities. Corp. Soc. Responsib. Environ. Manag., v.27, p.1552-1564, 2020. DOI: https://doi.org/10.1002/csr.1904

GIL, A. C.. Como elaborar projetos de pesquisa. 6 ed. São Paulo: Atlas, 2018.

GLASEROVÁ, J.. Differences in financial statements of business entities in the Czech Republic. Acta Universitatis Agriculturae et Silviculturae Mendelianae Brunensis, v.LXI, n.2, p.335-343, 2013. DOI: https://doi.org/10.11118/actaun201361020335 
GOMES, K. F.; BLAZQUEZ, A. L. T.; LEITE, E.; GARCÍA, G. G.. Contabilidad ambiental: Desde una Visión de Responsabilidad Social. International Journal of Professional Business Review, v.5, n.1, p.17-27, 2020.

KRIPKA, R. M. L.; SCHELLER, M.; BONOTTO, D. L.. Pesquisa documental na pesquisa qualitativa: conceitos $\mathrm{e}$ caracterização. Revista de Investigaciones Unad., v.15, p.119, 2016.

MINAS GERAIS. Lei $\mathbf{n}$. 6.310, de 08 de maio de 1974.

Autoriza o Poder Executivo a constituir e organizar empresa pública para o desenvolvimento e execução de pesquisas no setor da agropecuária. Belo Horizonte: DOE, 1974.

MINAS GERAIS. Empresa de Pesquisa Agropecuária de Minas Gerais. Referencial Estratégico. Belo Horizonte: EPAMIG, 2020.

MINAS GERAIS. Empresa de Pesquisa Agropecuária de Minas Gerais. Documentos Institucionais. Balanço Social 2016. Belo Horizonte: EPAMIG, 2017.

MINAS GERAIS. Empresa de Pesquisa Agropecuária de Minas Gerais. Documentos Institucionais. Balanço Social 2017 e 2018. Belo Horizonte: EPAMIG, 2018.
RAMOS, T. M.; SANTOS, T. R.. O balanço social como influência para uma sociedade empresarial sustentável: uma análise bibliométrica. Contexto - Revista do Programa de Pós-Graduação em Controladoria e Contabilidade da UFRGS, v.20, n.44, p.13-28, 2020.

SILVA, N. G.; CUNHA, F. B.; AZEVEDO, M.; MOXOTÓ, A. C. A. Balanço Social no Setor Público: Uma Análise Comparativa no Governo do Estado do Amazonas. Revista de Administração de Roraima - RARR, v.6, n.1, p.156-173-173, 2016. DOI: http://dx.doi.org/10.18227/22378057rarr.v6i1.3477

SILVA, E.; BERNARDO, D.; MENDONÇA, F.; NASCIMENTO, J. P.. Investimentos em Ações de Responsabilidade Social no Brasil: uma Análise Quantitativa. Revista de Administração, Sociedade e Inovação, v.1, p.53-69, 2015. DOI: https://doi.org/10.20401/rasi.1.1.21

SLOMSKI, V.. Manual de Contabilidade pública: um enfoque na contabilidade municipal. 2 ed. São Paulo: Atlas, 2003.

A CBPC - Companhia Brasileira de Produção Científica (CNPJ: 11.221.422/0001-03) detém os direitos materiais desta publicação. Os direitos referem-se à publicação do trabalho em qualquer parte do mundo, incluindo os direitos às renovações, expansões e disseminações da contribuição, bem como outros direitos subsidiários. Todos os trabalhos publicados eletronicamente poderão posteriormente ser publicados em coletâneas impressas sob coordenação da Sustenere Publishing, da Companhia Brasileira de Produção Científica e seus parceiros autorizados. Os (as) autores (as) preservam os direitos autorais, mas não têm permissão para a publicação da contribuição em outro meio, impresso ou digital, em português ou em tradução. 